\title{
Infantile hemangiomas
}

\author{
Katia Faustini, Joseph M. Lam MD
}

\section{Infantile hemangiomas are the most common type of vascular tumour in children}

Infantile hemangiomas present in about $4 \%-5 \%$ of infants, with predominance in female, preterm and white infants. ${ }^{1}$ They may present as superficial (Figure 1), subcutaneous (deep) or mixed lesions. Although they are most common in the head and neck region, they may appear anywhere on the skin or mucous membranes. Infantile hemangiomas differ from congenital hemangiomas in that they are often not present at birth, but appear within the first few days to months of life.

\section{A subset of hemangiomas can cause problems}

Whereas most hemangiomas require only observation, certain hemangiomas can be potentially limb- or life-threatening. Periorbital lesions may lead to complications such as astigmatism and optic atrophy, and laryngeal and tongue lesions can cause swallowing or respiratory impairment. Cosmetic disfigurement can occur with nasal-tip lesions. Hemangiomas may ulcerate, causing pain and bleeding. Certain cutaneous hemangiomas may be markers for underlying congenital anomalies (Figure 1). ${ }^{3,4}$ For example, lumbosacral segmental hemangiomas are associated with underlying spinal cord tethering and myelopathy, as well as other abnormalities. ${ }^{4}$ Multiple hemangiomas (>5) are a marker for visceral involvement. $^{5}$

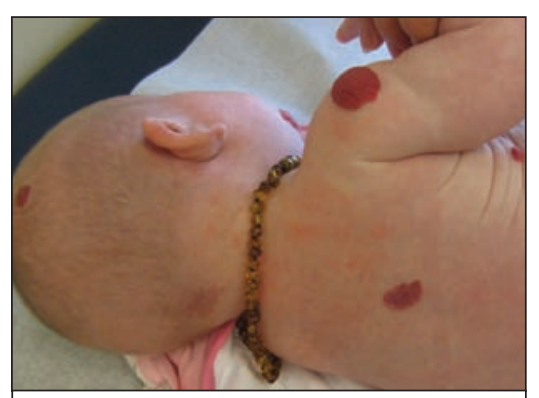

Figure 1: Multiple vascular papules and plaques are a marker for visceral involvement.
This article has been peer reviewed.

\section{Most infantile hemangiomas require only observation}

The natural history of hemangiomas involves early proliferation in which $80 \%$ of the growth occurs during the infant's first 3 months of life. After the infant is about 1 year of age, most hemangiomas undergo an involution period that progresses at a rate of $10 \%$ per year. ${ }^{2}$ Deep hemangiomas may have a longer growth and involution period. About $85 \%-90 \%$ of infantile hemangiomas will resolve completely by the time the child is 10 years of age, typically with minimal residual findings, and do not require treatment.

\section{Infants with problematic heman-} giomas should be referred early

Infants with hemangiomas require close observation during the first few weeks to months of life. Whereas most hemangiomas can be simply observed, infants with potentially problematic hemangiomas require rapid referral, ideally within this critical growth period. Referrals for high-risk hemangiomas that are growing should be considered urgent rather than routine by both the referring and the consulting physicians.

For references, please see Appendix 1, available at www.cmaj.ca/lookup /suppl/doi:10.1503/cmaj.121156/-/DC1

Competing interests: None declared.

Problematic hemangiomas can be effectively treated

Among experts, propranolol is becoming a first-line systemic treatment for problematic hemangiomas. ${ }^{6}$ It acts by inhibiting the growth phase of hemangiomas. Case series and randomized controlled studies have shown its benefit over systemic corticosteroids. ${ }^{8}$ It should be administered by an expert familiar with its use. Second-line treatments include systemic corticosteroids, $\alpha$-interferon and vincristine. ${ }^{5}$ Pulse-dye laser is effective for superficial and ulcerated hemangiomas, ${ }^{5}$ whereas topical timolol maleate gel shows promise in treating superficial lesions. ${ }^{9}$

Affiliations: From the Faculty of Medicine (Faustini), McGill University, Montréal, Que.; and the Departments of Pediatrics and of Dermatology and Skin Sciences (Lam), University of British Columbia, Vancouver, BC

Correspondence to: Joseph Lam, joseph.lam@ubc.ca

CMAJ 2013. DOI:10.1503/cmaj.121156 